\title{
Relationship between temporomandibular disorders and orthodontic treatment: A literature review
}

\author{
Ronaldo Antônio Leite', Joacir Ferreira Rodrigues², Maurício Tatsuei Sakima³, Tatsuko Sakima ${ }^{4}$
}

Objective: The objective of this study was to review the most recent studies from the last 15 years, in search of clinical studies that report the relationship between TMD and orthodontic treatment and/or malocclusion. Our intention was to determine whether orthodontic treatment would increase the incidence of signs and symptoms of TMD, and whether orthodontic treatment would be recommended for treating or preventing signs and symptoms of TMD. Methods: Literature reviews, editorials, letters to the editor, experimental studies in animals and short communications were excluded from this review. Were included only prospective, longitudinal, case-control or retrospective studies with a large sample and significant statistical analysis. Studies that dealt with craniofacial deformities and syndromes or orthognathic surgery treatment were also excluded, as well as those that reported only the association between malocclusion and TMD. Results: There were 20 articles relating orthodontics to TMD according to the inclusion criteria. The studies that associated signs and symptoms of TMD to orthodontic treatment showed discrepant results. Some have found positive effects of orthodontic treatment on signs and symptoms of TMD, however, none showed a statistically significant difference. Conclusions: All studies cited in this literature review reported that orthodontic treatment did not provide risk to the development of signs and symptoms of TMD, regardless of the technique used for treatment, the extraction or non-extraction of premolars and the type of malocclusion previously presented by the patient. Some studies with long-term follow-up concluded that orthodontic treatment would not be preventive or a treatment option for TMD.

Keywords: Orthodontics. Temporomandibular joint disorders. Dental occlusion.

Objetivo: revisar a literatura mais atual, dos últimos 15 anos, em busca de estudos clínicos que relatem a relação entre a disfunção temporomandibular (DTM) e o tratamento ortodôntico e/ou a má oclusão. A intenção foi verificar se o tratamento ortodôntico aumentaria o aparecimento de sinais e sintomas de DTM, e se o tratamento ortodôntico seria um recurso para o tratamento ou prevenção dos sinais e sintomas de DTM. Métodos: artigos dos tipos revisão de literatura, editorial, carta, estudo experimental em animais e comunicação foram excluídos dessa revisão. Foram incluídos artigos prospectivos, longitudinais, caso-controle ou retrospectivo com amostra maior, com relevante análise estatística. Estudos que abordassem deformidades e síndromes craniofaciais e tratamento por cirurgia ortognática também foram excluídos, bem como aqueles que relatassem apenas a associação entre má oclusão e DTM. Resultados: foram encontrados 20 artigos relacionando Ortodontia à DTM, segundo os critérios adotados. Os estudos, então, associando sinais e sintomas de DTM ao tratamento ortodôntico apresentaram resultados heterogêneos. Alguns encontraram efeitos positivos do tratamento ortodôntico para os sinais e sintomas de DTM; entretanto, nenhum deles apresentou diferença estatisticamente significativa. Conclusões: todos os estudos citados nessa revisão de literatura relataram que o tratamento ortodôntico não forneceu risco ao desenvolvimento de sinais e sintomas de DTM, independentemente da técnica utilizada para tratamento, da exodontia ou não de pré-molares e do tipo de má oclusão previamente apresentada pelo paciente. Alguns estudos realizados com acompanhamento em longo prazo concluíram que o tratamento ortodôntico não seria preventivo ou uma modalidade de tratamento para DTM.

Palavras-chave: Ortodontia. Transtornos da articulação temporomandibular. Oclusão dentária.

${ }^{1} \mathrm{PhD}$ in Otorhinolaryngology, UNIFESP. MSc in Dentistry, USP. Professor of Integrated Diagnostics at University of Franca.

${ }^{2} \mathrm{MSc}$ in Orthodontics, São Leopoldo Mandic. Professor of Orthodontics at the University of Franca.

${ }^{3}$ Post-doctorate, University of Aarhus, Denmark. Assistant Professor in the Department of Children's Clinic at FOAR (UNESP).

${ }^{4}$ Associate professor at FOAR-UNESP. Professor of the Specialization Course in orthodontics at the University of Franca, APCD - Regional of Araraquara and Dental Research Center at São Leopold Mandic.

Submitted: March 24, 2009 - Revised and accepted: October 20, 2010
How to cite this article: Leite RA, Rodrigues JF, Sakima MT, Sakima T. Relationship between temporomandibular disorders and orthodontic treatment: A literature review. Dental Press J Orthod. 2013 Jan-Feb;18(1):150-7.

" The author reports no commercial, proprietary or financial interest in the products or companies described in this article.

Contact address: Ronaldo Antônio Leite

Rua Francisco Marques, 698 - Sala 2 - Vila Nova - Franca/SP

CEP: 14405-342 - E-mail: dr.ronaldoleite@gmail.com 


\section{INTRODUCTION}

The problems associated with the diagnosis and management of temporomandibular disorders (TMD) have aroused interest to the orthodontist. The attention to signs and symptoms associated with TMD have modified the clinical management before and during orthodontic treatment. ${ }^{1}$

According to the American Academy of Orofacial Pain, the term temporomandibular disorder refers to a set of clinical problems that involve the masticatory musculature, the temporomandibular joint (TMJ) and associated structures, or both, being identified as the leading cause of non-dental pain in the orofacial region and is considered a subclass of musculoskeletal disorders. ${ }^{2}$

The signs and symptoms that indicate any abnormality of the TMJ are: Alteration of the mandibular movement, limitation of mouth opening, joint pain with mandibular function, constraint function, joint noises, asymptomatic radiographic changes of the TMJ and jaw locking with open mouth and closed mouth. ${ }^{3}$

The most common symptom associated with TMD is pain, usually located in the masticatory muscles, preauricular area and / or temporomandibular joint (TMJ). The pain is often aggravated by chewing or other functional activities. Limitation of mouth opening and movement, and the presence of joint noises are other common complaints in patients with TMD. ${ }^{2}$

There are several classification schemes that assist in the clinical diagnosis of TMD, e.g. schemes of the American Academy of Orofacial Pain. Almost all divide the TMD in subgroups: Muscular, articular and mixed. ${ }^{4}$ The role of malocclusion in the etiology of TMD has been reported as controversial in recent years. McNamara Jr., Seligman and Okeson ${ }^{5}$ published an extensive systematic review which concluded that there is a significant association between the presence of some occlusal factors (skeletal open bite, unilateral crossbite, absence of five or more teeth, deep overbite and severe overjet) and the presence of TMD signs and symptoms. Recently, a study in Brazil showed that the absence of bilateral canine guidance on lateral excursion and the presence of Class II malocclusion are important risk indicators for TMD development. ${ }^{6}$

Pellizoni et $\mathrm{al}^{7}$ based on the hypothesis raised by epidemiological studies, that there is an association between unilateral posterior crossbite (UPC) and disc displacement in TMJ, proposed a prospective study that evaluated the articular disc position and its configuration in children with functional UPC and individuals with normal occlusion using magnetic resonance imaging. All participants showed no clinical signs and symptoms of TMD.

Only an individual with articular TMD (disk displacement without reduction) was found. This one belonged to the study group and the crossbite was ipsilateral to the side of the disc displacement. These results suggest that internal disturbances of TMJ and UPC occur independently, or the magnitude of these disorders can not be identified by magnetic resonance imaging in this age group (6 to 13 years). ${ }^{7}$ Another explanation for UPC not implying in the TMJ disk displacement is the compensatory potential of the asymmetrical mandibular condyle growth or the remodeling of the articular fossa, which allows the articular disc to be in its normal position.

In the last decade, much effort has been placed to explain the supposed relationship between orthodontic treatment and TMD. Even with the availability of sophisticated and modern diagnostic tools such as magnetic resonance imaging, and scientific studies with long-term follow-up, it has not yet been possible to eliminate this existing controversy. ${ }^{8}$ Opinions differ between those who argue that orthodontic treatment increases the risk of onset of signs and symptoms of TMD and those who claim that this treatment would be a type of treatment for TMD, or at least to reduce the risk of the patient to develop it. ${ }^{9}$

The objective of this study was to review studies from the last 15 years, searching for clinical studies that report the relationship between TMD and orthodontic treatment and/or malocclusion, with the objective of determining if:

1. Orthodontic treatment would increase the incidence of signs and symptoms of TMD.

2. Orthodontic treatment would be an option for treating or preventing TMD symptoms and signs.

\section{MATERIAL AND METHODS}

A search was performed in the databases of International Literature in Health Sciences (MedLine), Latin American Literature and Caribbean Health Sciences (Lilacs) and Brazilian Dentistry Bibliography (BBO) using the following keywords: Orthodontics and temporomandibular disorder, in Portuguese and 


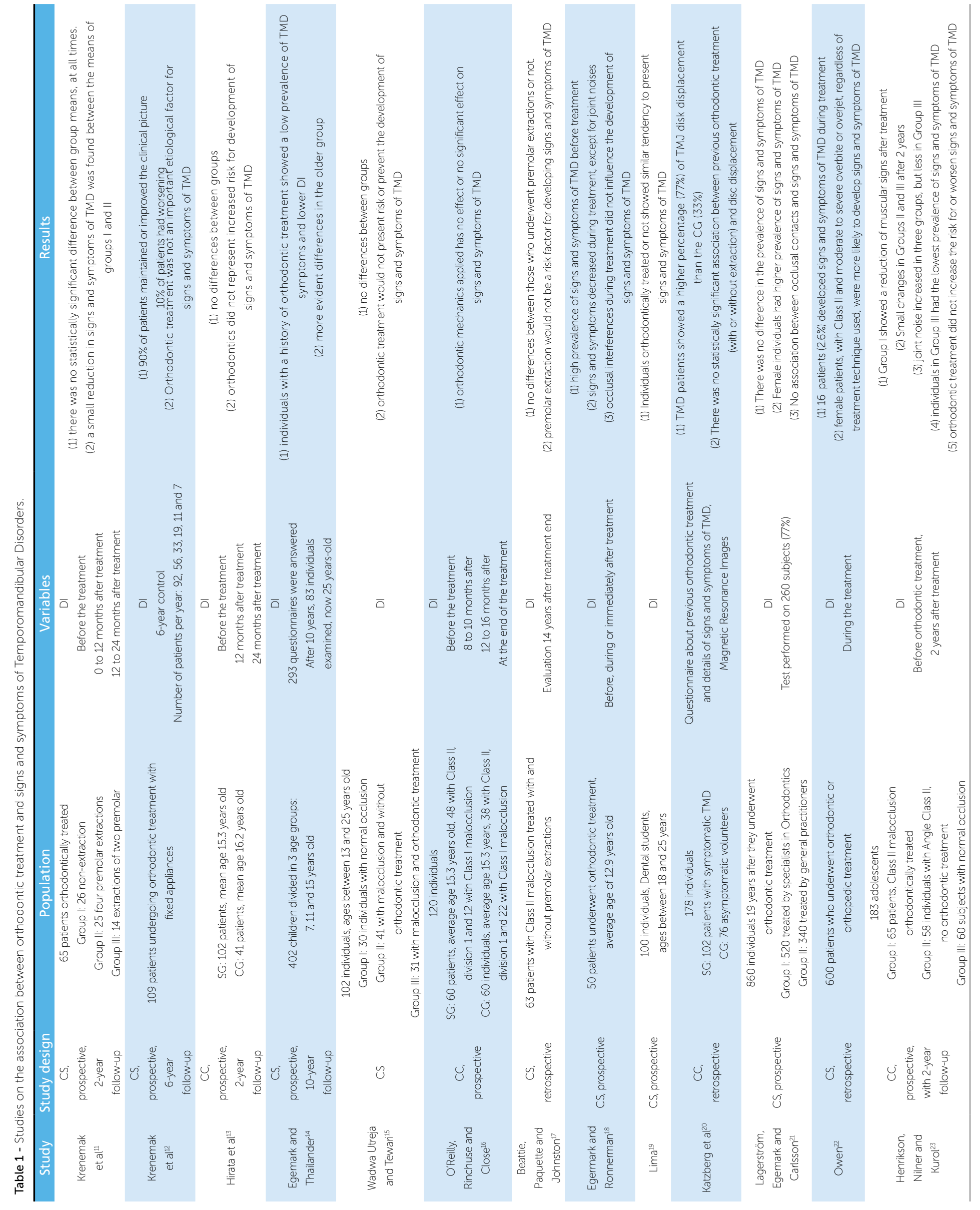




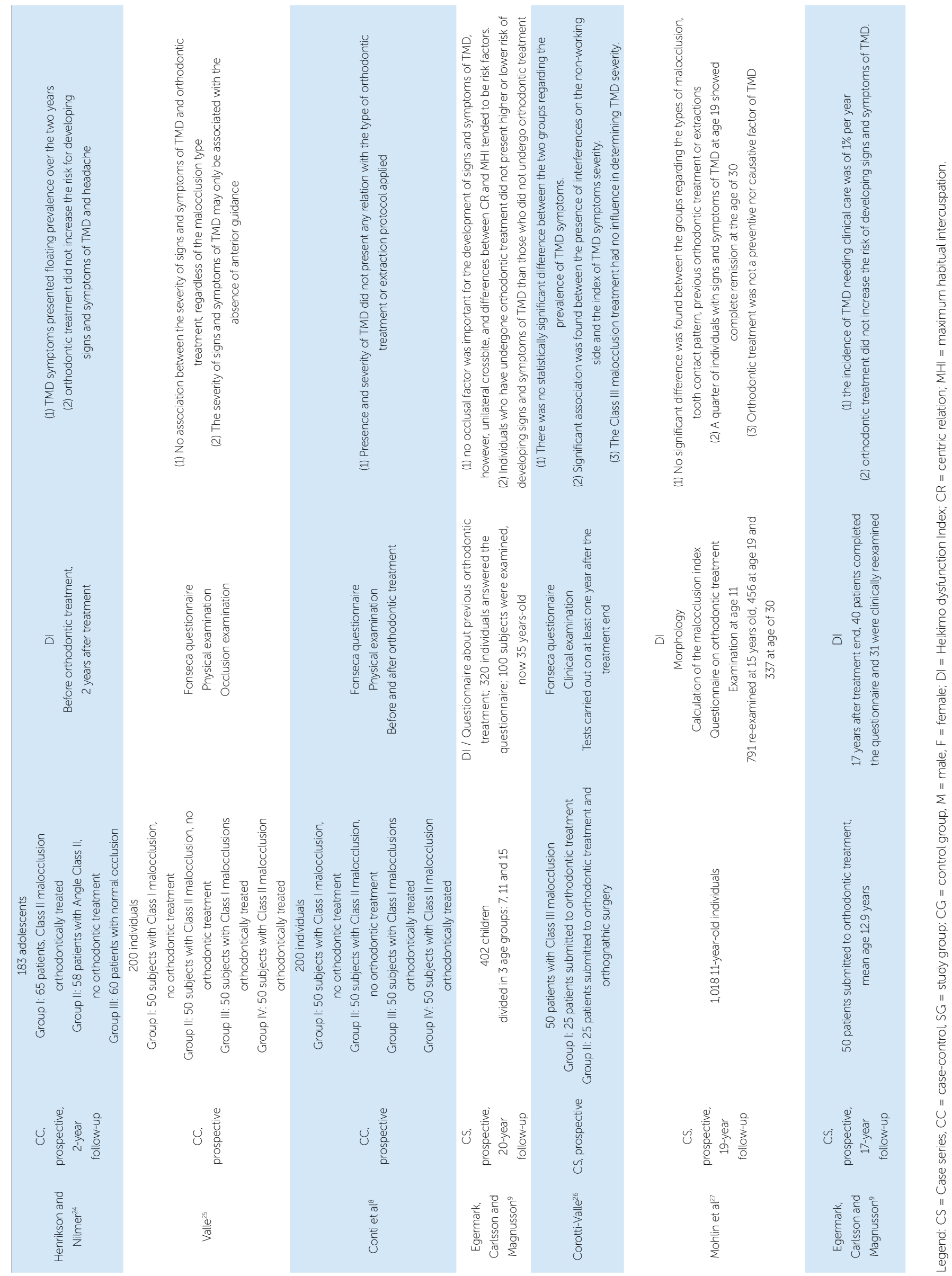


English, between January 1, 1992 to September 30, 2007. Articles like literature reviews, editorials, letters to the editor, experimental studies with animals and short communications were excluded from this review. Were included prospective, longitudinal, case-control or retrospective studies with larger samples and significant statistical analysis. These studies are the level B of evidence (moderate evidence). ${ }^{10}$

Studies that dealt with deformities and craniofacial syndromes or treatment by means of orthognathic surgery were also excluded, as well as those who reported only the association between malocclusion and TMD.

\section{RESULTS}

There were 20 articles found relating orthodontics to TMD according to the inclusion criteria. Table 1 presents a description of the studies found.

\section{DISCUSSION}

The restrictions imposed in this study in relation to databases and languages in the search of the literature relating to TMD and Orthodontics may have resulted in few studies. However, finding the best evidence, prioritizing the quality of the studies and the diagnosis of TMD and its division into subtypes could lead to clearer conclusions about this association.

One of the biggest problems found in the studies selected in this search for understanding the association between TMD and Orthodontics was the methodology they used to identify TMD. All studies, except that performed by Katzberget al, ${ }^{20}$ use the same tool to identify the signs and symptoms of TMD: the Helkimo index, published in 1974. There were few case-control studies, making it difficult to compare our data with regard to the signs and symptoms of TMD.

Professor Helkimo pioneered the development of indices to measure the severity of TMD, as well as pain in TMJ. In an epidemiological study, he developed an index divided into anamnesis, clinical and occlusal dysfunction. Through this index, he tried to identify, individually and in the population, the prevalence and severity of TMD, pain and occlusal instability. The protocol for the determination of this index consists of ten parameters: Emotional stress, parafunctional habits, mouth opening, lateralization of the jaw, joint sounds,
TMJ tenderness, palpation of the posterior muscles of the neck, palpation of masticatory muscles, maxillomandibular relationship and headaches. ${ }^{28}$

The Helkimo anamnesis index (AI) is based on a questionnaire where the individual reports the presence of symptoms of TMD. The results can generate three different levels of dysfunction: no symptoms; mild, moderate, or severe symptoms. The Helkimo clinical index $(\mathrm{CI})$ considers the functional evaluation of the stomatognathic system. According to the presence and/ or severity of clinical signs, individuals are assigned scores ranging from 0,1 or 5 points. The following aspects are observed: Range of mouth opening and lateral movements of the jaw; restricted jaw function; pain on palpation of masticatory muscles, TMJ and neck posterior muscles. The signs are also classified as none, mild, moderate or severe. The third index is called Helkimo occlusal index $(\mathrm{OI})$ and is obtained by analyzing the occlusion of the individual regarding the number of teeth, number of teeth in occlusion and occlusal interference between the RC and MHI positions. According to the data obtained for each item, scores 0,1 or 5 are assigned once again. The sum of the three indices generates the Helkimo dysfunction index (DI) (Table 2).

However, this tool, although widely used, is not able to diagnose and classify TMD, it only shows its signs and symptoms. There are limitations in using the DI, first because it gives equal importance to all the symptoms, it does not separate the muscular TMD from articular TMD, its categorization by points does not promote a continuous variable, reducing its specificity. Some symptoms are ignored, such as the type of joint noises and when they occur, and some muscle regions. Even though this index is able to document the signs and symptoms of TMD in the population, the organization of data from these indices seems not to benefit other areas of Epidemiology, for example, in understanding TMD etiology. ${ }^{29}$ As an example of how the index might be flawed, if a person has more than 15 episodes of headache per month, and she/he is very tense and present pain on palpation of the posterior muscles: He/she would be classified as presenting with moderate TMD, without even having a single peculiar sign or symptom of TMD - i.e., the person might not even present TMD.

Bevilaqua-Grossi et $\mathrm{al}^{29}$ suggested that a way to identify patients who really need TMD treatment 
Table 2 - Degree of temporomandibular disorder according to Helkimo dysfunction Index.

\begin{tabular}{rrr}
\hline Helkimo index (scores) & Degree of Temporomandibular Disorders \\
0 to 20 & No signs and symptoms of TMD \\
21 to 30 & Mild signs and symptoms of TMD \\
31 to 40 & Moderate signs and symptoms of TMD \\
41 or more & Severe signs and symptoms of TMD \\
\hline
\end{tabular}

would be to determine the frequency and intensity of signs and symptoms of TMD. The authors suggest using the questionnaire proposed by Fonseca ${ }^{30}$ (Table 3) and a clinical examination assessing the range of mouth opening and the tenderness of masticatory muscles and TMJ to palpation. According to the authors, Fonseca questionnaire $^{30}$ is a simple questionnaire, without pretension to diagnose TMD, but it can be a useful tool in observing the symptoms reported by patients. Not only the frequency of symptoms should be checked, but also its severity, aiming to identify those patients that require treatment for TMD. Three studies conducted in Brazil and reviewed in the present article used the Fonseca anamnesis questionnaire in order to discriminate patients who would present TMD, followed by physical examination.

Since 1992, to facilitate the conduction of clinical research, researchers in epidemiological and clinical studies or aiming to determine samples in randomized and controlled trials, use a classification scheme called the Research Diagnostic Criteria for Temporomandibular Disorders (RDC/TMD) which diagnoses the presence of TMD. The RDC/TMD is a tool for clinical diagnostic criteria, measurable and reproducible, that aims at identifying subgroups of patients with TMD. The RDC/TMD classifies the most common types of TMD into three subgroups: Disorders of the masticatory muscles (myofascial pain), TMJ internal derangement (disk displacement), and degenerative diseases of the TMJ (arthralgia, arthritis and osteoarthritis). The use of the RDC depends on anamnesis and physical examination data, making use of questionnaires, surveys and specifications. ${ }^{31}$ The study by Katzberg et $\mathrm{a}^{20}$ used this tool to diagnose disk displacement with reduction in its sample.

Thus, none of the studies associating TMD and Orthodontics diagnosed TMD, they only observed the presence of signs and symptoms. Therefore, one cannot conclude from these studies whether the
TMD would be a condition that motivates individuals to seek treatment for their functional problems. There is a large disparity between the signs and symptoms of TMD (which can be present in up to $68 \%$ of the population $)^{32}$ and TMD diagnosis (8$15 \%$ of women and $3-10 \%$ of men). ${ }^{33}$

Another difficulty in analyzing the signs and symptoms of TMD in the cited studies is the episodic or floating character of the appearance of these symptoms observed in long-term studies. The prevalence varied among the analysis performed on different occasions. Krenemak et $\mathrm{a}^{12}$ showed in their sample that $90 \%$ of patients who developed signs and symptoms of TMD,

Table 3 - Fonseca ${ }^{30}$ questionnaire for anamnesis of temporomandibular disorder.

\begin{tabular}{|c|c|}
\hline 1 & Do you have difficulty to open your mouth? \\
\hline 2 & $\begin{array}{c}\text { Do you feel difficulty to move your jaw sideways? } \\
\text { To the right? To the left? To both sides? }\end{array}$ \\
\hline 3 & Do you have muscle fatigue or pain when chewing? \\
\hline 4 & Do you often have headaches? \\
\hline 5 & Do you feel pain in the neck or torticollis? \\
\hline 6 & $\begin{array}{l}\text { Do you have ear ache or in the } \\
\text { temporomandibular joints region (TMJ)? }\end{array}$ \\
\hline 7 & $\begin{array}{l}\text { Have you noticed if you have TMJ sounds when chewing or } \\
\qquad \text { when you open your mouth? }\end{array}$ \\
\hline 8 & $\begin{array}{l}\text { Have you noticed if you have any habits like pushing and/or } \\
\text { grinding teeth, chewing gum, biting lip or pencil, nail biting? }\end{array}$ \\
\hline 9 & Do you feel that your teeth do not fit together well? \\
\hline 10 & Do you consider yourself a tense or nervous person? \\
\hline
\end{tabular}

Anamnestic index to classify the categories of severity of symptoms of TMD.

\begin{tabular}{cc}
\begin{tabular}{c} 
Anamnestic index to classify the categories of severity of symptoms of TMD. \\
\hline $\begin{array}{c}\text { Categories of severity of } \\
\text { TMD symptoms }\end{array}$ \\
Ro signs and symptoms threshold to classify \\
the categories
\end{tabular} \\
Mild signs and symptoms & 0 to 15 \\
Moderate signs and symptoms & 20 to 40 \\
Severe signs and symptoms & 45 to 65 \\
\hline
\end{tabular}


after two years maintained or improved the situation, while $10 \%$ worsened. While Mohlin et $\mathrm{al}^{27}$ showed that $25 \%$ of patients at the end of 19 years of follow-up, had complete remission of signs and symptoms of TMD. The signs and symptoms appear to improve with time, except for joint noises, which increased after 2 years of follow-up. ${ }^{23}$ Still, Owen ${ }^{22}$ reported that $2.6 \%$ of the patients developed signs and symptoms of TMD during orthodontic treatment. Egermark, Carlsson and Magnusson $^{9}$ in a 17 years follow-up study, showed that $1 \%$ of the sample required TMD clinical care per year.

The studies associating signs and symptoms of TMD with orthodontic treatment showed discrepant results. Some studies have found positive effects of orthodontic treatment on the signs and symptoms of TMD, however, none showed statistically significant results. ${ }^{9,11,12,14,23}$ All studies cited in this literature review reported that orthodontic treatment did not provide risk to the development of signs and symptoms of TMD, regardless of the technique used for treatment, whether or not the extraction of premolars was performed, and the type of malocclusion previously presented by the patient. $8,9,11-25,27$ Some long-term studies concluded that the orthodontic treatment would not be preventive or a treatment modality for TMD. ${ }^{9,15,27}$ Henrikson and Nilmer ${ }^{24}$ suggested that due to the fluctuating character of the signs and symptoms of TMD, and as orthodontic treatment is not effective in treating TMD, a conservative and reversible approach should be adopted in the treatment of TMD, which agrees with the guidelines of the American Academy of Orofacial Pain. ${ }^{2}$
Some articles also mentioned the relationship between malocclusion and signs and symptoms of TMD. There was no statistically significant association between malocclusions and signs and symptoms of TMD. ${ }^{18,21,25,27}$ However there was a trend that patients with Class II malocclusion with overbite or moderate to severe overjet, ${ }^{22}$ absence of anterior guidance, ${ }^{25}$ unilateral crossbite and difference between $\mathrm{CR}$ and $\mathrm{MHI}^{9}$ could present a greater number of signs and symptoms of TMD. Still, Corotti-Valle ${ }^{26}$ found in their sample a significant association between severity of symptoms of TMD and interference in the balance side.

\section{CONCLUSIONS}

From the studies found in the literature review, we concluded that the orthodontic treatment - regardless of the technique used and whether or not the extraction of premolars during treatment - does not increase the signs and symptoms of TMD and therefore it is not a risk factor for its development. The orthodontic treatment does not appear to be a valuable resource for treating or preventing the onset of signs and symptoms of TMD. There is the need to improve the methodology used in studies that seek to demonstrate the association between TMD and orthodontic treatment so they can be less contradictory. Features such as controlled trials, longitudinal studies and tools that can diagnose TMD and divide it into subtypes (such as muscular, articular and mixed), seem to be necessary for a better understanding of this association. 


\section{REFERENCES}

1. Durso BC, Azevedo LR, Ferreira JTL. Inter-relação Ortodontia X Disfunção da articulação temporomandibular. J Bras Ortodon Ortop Facial. 2002;7(38):155-60

2. Okeson JP. Dor orofacial: guia para avaliação, diagnóstico e tratamento. São Paulo: Quitenssence; 1998.

3. Siqueira JTT. Disfunção temporomandibular: classificação e abordagem clínica. In: Siqueira JTT, Teixeira MJ. Dor orofacial: diagnóstico, terapêutica e qualidade de vida. Curitiba: Ed. Maio; 2001. p. 373-404

4. Okeson JP. Current diagnostic classification schema and assessment of patients with temporomandibular disorders. Oral Surg Oral Med Oral Pathol Oral Radiol Endod. 1997:83:61-4.

5. McNamara Jr JA, Seligman DA, Okeson JP. Occlusion, orthodontic treatment, and temporomandibular disorders: a review. J Orofacial Pain. 1995;9(1):73-90.

6. Selaimen CMP, Jeronymo JC, Brilhante DP, Lima EM, Grossi PK, Grossi ML. Occlusal risk factors for temporomandibular disorders. Angle Orthod. 2007;77(3):471-7.

7. Pellizoni SEP, Salioni MA, Juliano Y, Guimarães AS, Alonso LG. Temporomandibular joint disc position and configuration in children with functional unilateral posterior crossbite: a magnetic resonance imaging evaluation. Am J Orthod Dentofacial Orthop. 2006;129(6):785-93.

8. Conti A, Freitas M, Conti P, Henriques J, Janson G. Relationship between signs ans symptoms of temporomandibular disorders and orthodontic treatment: a cross-sectional study. Angle Orthod. 2003;73(4):411-7.

9. Egermark I, Carlsson GE, Magnusson T. A prospective long-term study of signs and symptoms of tempomandibular disorders in patients who received orthodontic treatment in childhood. Angle Orthod. 2005;75(4):645-50.

10. Malterud K. Qualitative research: standards, challenges, and guidelines. Lancet. 2001;11:483-8.

11. Kremenak CR, Kinser DD, Harman HA, Menard CC, Jakobsen JR. Orthodontic risk factors for temporomandibular disorders (TMD) I: premolar extractions. Am J Orthod Dentofacial Orthop. 1992;101(1):13-20.

12. Kremenak CR, Kinser DD, Melcher TJ, Wright GR, Harrison SD, Ziaja RR, et al. Orthodontics as a risk factor for temporomandibular disorders (TMD) II. Am J Orthod Dentofacial Orthop. 1992;101(1):21-7.

13. Hirata RH, Heft MW, Hernandez B, King GJ. Longitudinal study of signs of temporomandibular disorders (TMD) in orthodontically treated and nontreated groups. Am J Orthod Dentofacial Orthop. 1992;101(1):35-40.

14. Egemark I, Thilander B. Craniomandibular disorders with special reference to orthodontic treatment: an evaluation from childhood to adulthood. Am J Orthod Dentofacial Orthop. 1992;101(1):28-32

15. Wadhwa L, Utreja A, Tewari A. A study of clinical signs and symptoms of temporomandibular dysfunction in subjects normal occlusion, untreated, and treated malocclusions. Am J Orthod Dentofacial Orthop. 1993;103(1):54-61.

16. O Reilly M, Rinchuse DJ, Close J. Class II elastics and extractions and temporomandibular disorders: a longitudinal prospective study. Am J Orthod Dentofacial Orthop. 1993;103(5):459-63.

17. Beattie JR, Paquette DE, Johnston LE. The functional impact of extraction and nonextraction treatments: a long-term comparison in patients with borderline, equally susceptible Class II malocclusions. Am J Orthod Dentofacial Orthop. 1994;105:444-9.
18. Egemark I, Ronnerman A. Temporomandibular disorders in the active phase of orthodontic treatment. J Oral Rehabil. 1995;22:613-8.

19. Lima DR. Estudo de prevalência de disfunção craniomandibular segundo o índice de Helkimo tendo como variáveis: sexo, faixa etária e indivíduos tratados ou não ortodonticamente [dissertação]. São José dos Campos (SP): Universidade Estadual Paulista; 1995.

20. Katzberg RW, Westesson PL, Tallents RH, Drake CM. Orthodontics and temporomandibular joint internal derangement. Am J Orthod Dentofacial Orthop. 1996:109(5):515-20.

21. Lagerström L, Egemark I, Carlsson GE. Signs and symptoms of temporomandibular disorders in 19-year-old individuals who have undergone orthodontic treatment. Swead Dental J. 1998;22(5-6):177-86.

22. Owen $\mathrm{AH}$. Unexpected temporomandibular joint findings during fixed appliance therapy. Am J Orthod Dentofacial Orthop. 1998:113(6):625-31.

23. Henrikson T, Nilner M, Kurol J. Signs of temporomandibular disorders in girls receiving orthodontic treatment. A prospective and longitudinal comparison with untreated Class II malocclusions and normal occlusion subjects. Eur J Orthod. 2000;22:271-81.

24. Henrikson T, Nilner M. Temporomandibular disorders and the need for stomatognathic treatment in orthodontically treated and untreated girls. Eur $\mathrm{J}$ Orthod. 2000:22(3):283-92.

25. Valle KM. Estudo comparativo da oclusão e da sua relação com as Disfunções Temporomandibulares (DTM) em jovens com e sem tratamento ortodôntico [Dissertação]. Bauru (SP): Universidade de São Paulo; 2000.

26. Corotti-Valle KM. Avaliação da prevalência da disfunção temporomandibular (DTM) em pacientes tratados das más oclusões de Classe III, submetidos a tratamento ortodôntico e orto-cirúrgico [tese] Bauru (SP): Universidade de São Paulo; 2004

27. Mohlin BO, Derweduwen K, Pilley R, Kingdon A, Shaw WC, Kenealy P. Malocclusion and temporomandibular disorder: a comparison of adolescents with moderate to severe dysfunction with those without signs and symptoms of temporomandibular disorder an their further development to 30 years of age. Angle Orthod. 2004;74(3):319-27

28. Helkimo M. Studies on function and dysfunction of the masticatory system. II. Index for anamnestic and clinical dysfunction and occlusal state. Swed Dental J. 1974:67:101-21.

29. Bevilaqua-Grossi D, Chaves TC, de Oliveira AS, Monteiro-Pedro V. Anamnestic index severity and signs and symptoms of TMD. Cranio. 2006;24(2):112-8.

30. Fonseca DM. Diagnóstico pela anamnese da disfunção craniomandibular. Rev Gaúcha Odontol. 1994;42:23-8.

31. Dworkin SF, Le Resche L. Research diagnostic criteria for temporomandibular disorders. J Craniomandib Disord. 1992;6(4):301-55

32. Pedroni CR, Oliveira AS, Guaratini MI. Prevalence study of signs and symptoms of temporomandibular disorders in university students. J Oral Rehabil. 2003;30:283-9.

33. Le Resche L. Epidemiology of temporomandibular disorders: implications for the investigation of etiologic factors. Crit Rev Oral Biol Med. 1997;8(3):291-305. 